\title{
Music of the Hmong in the Northern Region of the Lao People's Democratic Republic
}

\author{
Boonloy Juntong ${ }^{1}$, Chareonchai Chonpairot ${ }^{1}$ \& Narongchai Pidokrajt ${ }^{2}$ \\ ${ }^{1}$ College of Music, Mahasarakham University, Khamriang Sub-District, Kantarawichai District, Maha Sarakham, \\ Thailand \\ ${ }^{2}$ College of Music, Mahidol University, Salaya, Phutthamonthon, Nakhonpathom, Thailand \\ Correspondence: Boonloy Juntong, College of Music, Mahasarakham University, Khamriang Sub-District, \\ Kantarawichai District, Maha Sarakham 44150, Thailand. E-mail: bjuntong153@outlook.com
}

Received: May 15, 2014 Accepted: June 13, 2014 Online Published: June 26, 2014

doi:10.5539/ach.v6n2p222

URL: http://dx.doi.org/10.5539/ach.v6n2p222

\begin{abstract}
The purposes of this qualitative research were to investigate musical instruments, musical bands and lyrics of music among Hmong hill tribes in the northern region of the Lao People's Democratic Republic, to investigate the role of Hmong music in the northern region of the Lao People's Democratic Republic and to investigate musical preservation in the northern region of the Lao People's Democratic Republic. Results show that Hmong music in the Lao People's Democratic Republic has its own specific identity that has been handed down from generation to generation. The musical instruments contain their own identity and are produced from natural products. The instruments are believed harbor supernatural power. The musical instruments are divided into two categories: percussion and windpipes. Keng is the most important musical instrument for ritual ceremonies. Usually, Hmong musical bands are employed for ritual activities rather than recreation. Musical tunes are always played in continuous patterns for one round and repeated depending on the emotion of the musicians. The tone of musical tunes is comprised of short and long sounds. Musicians have their own freedom in creating different sounds in various musical tunes and their playing has no exact form. It depends on musicians to insert sounds or teach various playing techniques. As Hmong hill tribe people believe in spirits, their music plays an active role as a means to communicate with gods and the spirits of dead people. They believed that spirits are from the natural environment. So, Hmong hill tribe people believe that their music is a means to communicate with deceased people. This belief has made Hmong people adore their musical instruments and the musical instruments have never been changed. Musical instrument makers are native Hmong. Hmong music is still alive and active in various ritual activities as a means of preserving beliefs, culture and rites.
\end{abstract}

Keywords: music, Hmong people, Lao People's Democratic Republic, role, preservation

\section{Introduction}

Hmong or Hmoob communities have a long history of migration from central China in the Huang Ho or Yellow river valley down to Lanna (Culas, 1975). At present, some Hmong groups remain in southwest China, northern Myanmar, Laos, Vietnam and Thailand. In the $13^{\text {th }}$ century, the Manchu dynasty was in power and tried to eradicate the Hmong people. The fierce fighting took place in various places and times such as Pang-Yoon in 1466, in Kwai-Jaow B.E. 1733-1735, Schuan and Kwai-Jao in 1763-1775 and in 1881. Each war caused great numbers of Hmong casualties, so they moved south through Yu-Nan and the Reol River in Tougin. However, they had to fight again with Yuan tribes and pulled back up to the hills and high plateaus in Sip-song Ju Thai and Sip-song Panna. Hmong people spent only a few decades migrating to various places such as northern Vietnam and Laos. Hmong experts indicate that Hmong people moved into Nong-Had town Chieng-Quang county of the Lao People's Democratic Republic from 1810-1820. Also some groups of Hmong migrated into Toong-Hai-Hin in Laos and Dien-Bien-Fu in Vietnam and settled. From their long history of migration, Hmong people carried on their deep and clear culture as their own cultural identity. They prefer to live in high mountains at an altitude of at least 4,000 feet above sea level. The Hmong people live at the highest level in the mountains compared to other hill tribes (Patagratch, 2005).

According to Hmong records, Hmong people have migrated continuously. They compare their way of living to dried leaves dependent on wind power. Various causes of migration are war, need for farming land and tribal 
conflict. Wherever they move, Hmong people continue their cultural identity. Hmong social norms are in family groups. Marriage is the means to tie close relationships. They keep their own culture, way of life, belief and customs very firmly with great individual identity (Chantawanitch \& Pliensri, 2010). Their music is a kind of culture dealing with their way of life and a means of dealing with spirits and sacred things that help create their happiness. Modern musical culture cannot influence their traditional music. There is no evidence to prove when their original music started. The main function of their music is for cremation rituals, while music for pleasure is a secondary function. The Hmong and their music have closed relations and music is firmly tied into the life of the Hmong people (Vorreiter, 2009). However, because of the effect on globalization under various media such as T.V., radio and multimedia there may be threats and changes to the music and culture of the Hmong in the future.

\section{Research Methodology}

This study was an ethnomusicology qualitative research aimed at investigating musical instruments, musical bands and lyrics of music among Hmong hill tribes in the northern region of the Lao People's Democratic Republic, investigating the role of Hmong music in the northern region of the Lao People's Democratic Republic and investigating musical preservation in the northern region of the Lao People's Democratic Republic. Data was collected through documents and field study using surveys, observation and interviews. The collected data was analyzed and presented in a descriptive style. The process was divided into three stages: research preparation, field study data collection and data manipulation and analysis.

\subsection{Research Preparation}

The confines of this study were limited. The focus was on musical instruments, musical bands, songs, musical roles and preservation of Hmong musical culture in people in the northern region of the Lao People's Democratic Republic. The research team selected the location using purposive sampling. The locations chosen were Nong-Had town in Chowg Kwaa County, Luang Pra Bang Town, Pon-Sa Wan Town and Piang Town in Chaiyaburi County. These places were selected on the grounds that their population maintained their original culture strictly by continued incorporation in their everyday lives. The population of this study was the Hmong people living in the northern region of the Lao People's Democratic Republic. The sample group of study was selected using a purposive sampling method in order to obtain effective subjects as informants. The sample group was divided into 3 sub-groups: Key informants, casual informants and general informants. The research team used a qualitative research method to collect document data and field study data by means of survey, observation, interview, group discussion. The collected data was then analyzed by typological analysis and an analytic induction technique. The research was conducted from July 2011 to June 2013.

\subsection{Research Tools}

The research team used the following research tools. Basic survey was used to collect basic information regarding population, housing, community buildings and groups. Survey was conducted to gather information on important figures, musicians, musical bands and the Hmong musical instruments in the study area. This investigation used both structured interviews and unstructured interviews (general conversation). The structured interview technique was employed to gather specific information from key informants, casual informants and general informants. Topics covered were historical background, general physical geography, economy, government, technology, religion, beliefs and rituals, as well as music, musicians, musical instruments, musical bands, songs, changes to musical culture and the effects of globalization. These topics were covered in accordance with the research framework. Domestic and international Hmong musical experts were interviewed. Participant observation was undertaken to observe the general situation within the musical community dealing with culture, ritual, community behavior and people. Focus groups were arranged with senior musicians, tribe leaders, community leaders, scholars, musical band leaders, musicians and members of the general population to deal with Hmong musical culture in the focus communities to identify preservation approaches and ways to enhance Hmong musical culture. The research team collected basic information from various kinds of document such as books, articles, journals, scholarly documents, internet databases from within the country and abroad. All collected data was classified and grouped in accordance with the research aims. Data analysis included illustrations and local song notes, as well as international song notes. The songs were analyzed in descriptive form using computer programs for tonal analysis.

\section{Results}

The study on Hmong music in the northern region of the Lao People's Democratic Republic revealed that Northern Laos Hmong music has its own identity, which has been handed down from generation to generation. The origins of the music cannot be confirmed, except by legends made and passed on by word of mouth. Hmong 
musical instruments have their own identity and are created using natural materials found in the local area. The musical instruments are sacred and respected by the Hmong people. The musical instruments are divided into two categories: percussion, such as the Jua and windpipes, such the Keng Jaang and Yaang. The Keng is the most important musical instrument used in Hmong ritual music.

The music of Hmong people living in the northern region of the Lao People's Democratic Republic is for ritual activities more than for recreation. In cremation ceremonies, only two musical instruments are used, Keng and Jua. The number of musicians depends on the social rank of the tribe member. If the dead person was important, six musicians are required. For infant cremation ceremonies only one or two musicians are used.

The lyrics of Hmong songs have been handed down for generations with no identifiable composer. Most of the words in Hmong songs are the continuation of words in sentences. When the song has ended, the musicians will replay it again and again, depending on their mood. Hmong lyrics are in tandem with the main structure of the tune, comprising short notes and long notes to make phrases. The drone of the Keng is incorporated into all songs and constitutes the tribal identity. The musicians have a lot of freedom during the song, so the song composition depends on the individual players, who insert the sounds and techniques that best illustrate their ability. However, every Hmong song had a main structure. The musicians play continuous tunes, depending on the steps of the particular ritual. There are few musicians and they are not employed or registered by any state or private organization. All Hmong musicians are independent and they alone are responsible for preserving Hmong musical culture for the next generation.

\subsection{The Function of Hmong Music in the Northern Region of the Lao People's Democratic Republic}

Hmong people living in the northern region of the Lao People's Democratic Republic respect the spirits. They believe that all spirits are their own ancestors. These spirits may live anywhere, such as rivers, streams, the sky, trees, mountains, fields and houses. Hmong music is believed to be the only means of the Hmong people to communicate with all of their ancestors. They attach most importance to the musical instruments, especially the Keng, which is the Hmong identity. The study found that opportunities are limited to perform Hmong music in the northern region of the Lao People's Democratic Republic. The music is mainly played for rituals and less often for fun. The importance of Hmong music in the northern region of the Lao People's Democratic Republic lies in the cremation ritual. If there is no music in the ritual, other activities cannot be performed.

\subsection{The Preservation of Hmong Musical Culture}

\subsubsection{The Preservation of the Musical Instruments}

The study revealed that Hmong musical instruments are handmade and have been handed down from ancestors. The instruments are never changed. The instrument makers invented their own equipment to create musical instruments and the techniques were also handed down to family members, as well as other interested people.

\subsubsection{The Preservation of the Musical Bands}

The study indicated that Hmong musicians the field or garden to practice and rehearse the music. They believe that their music is not supposed to be played in the house or village because it brings bad luck or omens. As Hmong music is performed for various cultural occasions, it seems the future of Hmong music will only last forever if the Hmong people firmly keep the culture of their tribe. Nevertheless, this study showed that Hmong music has a clear future because there are many young Hmong musicians participating in the music performance. Also, ordinary Hmong people looked up to Hmong musicians with great honor for maintaining the Hmong culture.

\subsubsection{The Preservation of Hmong Songs}

The study found that Hmong musical experts play a great part in preserving songs. They help train Hmong music and songs to the interested people free of charge. Young Hmong blood musicians are trained to perform their music on various occasions but they strictly adhere to the original ways of playing.

\subsubsection{The Preservation of Hmong Musical Knowledge and Musical Playing Techniques}

The study disclosed that the Hmong musical playing technique transfer was done from generation to generation without notes or records of symbols or standards. The techniques are inherited on a one to one basis between a teacher and a student in the tribe. At present, training of new Hmong musicians is divided into two approaches: young Hmong musicians play the music by themselves or the family sends their children to take part in musical training. At present most young Hmong musicians are males. Actually, there may be some females interested in music, but they are ashamed to take part. However in the near future and if their attitude changes more females could be found in Hmong musical bands. 


\section{Discussion}

For the domain of musical instruments, musical bands and musical tunes, Hmong hill tribe people have a firm background in spiritual belief and respect the sacred concepts of their hill tribe group. There are no names for the composers of their songs, which have been handed down through oral tradition. The main purpose of their musical culture is for ritual activities in accordance with their beliefs. The secondary purpose of their music is recreation. This is consistent with the theory of Franz Boas (1914), who stated that the culture of each society is influenced by their historical identity. In certain societies there are various sides, including a specific base of that culture.

Hmong musical tunes are continually repeated after one round according to the emotion of the musician. Usually, their musical tune comes from Hmong poems, which may be named Song poems. They can be short or long. This gives the content of Hmong music a specific identity. Keng is in the musical category of aerophone. There are two types of Keng: Tao-Keng and Dee Keng. Keng are made from natural environment products in the local are. The percussion instrument is the Jua. According to Boonloy Juntong's research (2003), Hmong people have their own musical instruments made from natural materials, which they believe to be sacred due to the spiritual power within. This is a belief specific to Hmong hill tribe groups.

Hmong hill tribe musical tunes are composed by Hmong musicians or poets containing subject matter and rhythms specifically adapted for Hmong ritual ceremonies. These styles have been handed down from generation to generation and recalled from memory. The identity of Hmong music is as follows: 1) there is only one style of playing; 2) musical instruments and equipment to create musical instruments are developed by the Hmong people; 3) the songs are pentatonic; 4) sound standards have less focus than functions.

Music plays an active role in the life of Hmong hill tribe people and has a deep connection with Hmong ritual activities. Hmong music is employed as a means to communicate with spirits and sacred things. This corresponds to the study of Jean Mottin (1980). The research indicated that Hmong people have no permanent god such as Christians and Muslims. Hmong believe in spirits. This has had a great influence on Hmong lifestyle. Hmong people respect animism. This belief originated in various ritual activities, and they use music as the means to perform ritual ceremonies. They pay most respect to the music and tribe leaders, as well as ritual performers. This study is in accordance with Radcliffe-Brown's (1940) structure and function theory, which stated that components in the structure of a society must be in harmony. So, the customs and cultures of any institution should continually support one another. Society and culture should be the equipment linking social members to participate effectively in social activities. The role of Hmong music should contain the following characteristics: 1) Music illustrating tribal identity, such as language, dressing and way of life; 2) music communicating between humans and non-living things (spirits); 3) music closely linked to nature - not only materials used to make musical instruments but also natural sounds used to compose songs; 4) music showing the compromise between nature and original tribal beliefs and customs; 5) music reflecting the love of music in all humans.

The study revealed that Hmong music can be preserved by accumulating musical instruments used from the past to the present. The location of the building housing the instruments should include the history and development of Hmong music. There must be group of people made responsible for care of music instruments, musical repairs, as well as propagating and supporting transmission of traditional knowledge. The development of learning about Hmong music should be encouraged to make people realize the importance of Hmong musical culture. Among Hmong hill tribe groups, committees of musical instrument makers should be organized and a database system created. An instrument creation and repair manual should also be created. Public relations should be set for people who are interested in Hmong music to practice how to play the instruments. All of these should be done systematically and are in accordance with the study of Mingkwan Chonpairote (2008), which indicated that establishment of a museum was vital to the dissemination of culture and customs of the community.

Hmong musical learning centers could be established to teach the nature of Hmong musical songs as well as their lyrics, types and benefit in ritual activities. The learning of Hmong music should be done in real situations. Also, song notes and lyrics should be recorded in various databases. The encouragement of Hmong youth to participate in the program should be organized as well as the creation of a Hmong musical handbook. This would be in accordance with the study of Nirut Kaewla (2011). Kaewla revealed that to revive Hmong music knowledge at Ban Nong Hoi, Hmong musical clubs should be set for interested people. For people who have a musical background, a committee for musical clubs should be encouraged. Community schools should provide resources to teach and demonstrate Hmong music. Teachers of music in schools must know Hmong musical 
history as well as the production of Hmong musical exercise books for students. This would help creation of pride in their tribal group.

The identity of Hmong hill tribe music could be under threat from the emergence of new media, such as television and radio, in homes. Therefore, the state and private sectors could participate and help preserve the culture and customs of local tribes. They should be encouraged to have pride in their tribal culture with a clear program. Besides, research into culture and customs should be conducted, since there are many tribal customs that have never been studied.

The research team would like to highlight a number of interesting points for further study. This research did not investigate techniques of playing and important features of ritual musical performances. Also, this study did not mention singing and music technique combinations. So, further research should cover these points. Comparisons should be made between Hmong music and the music of other hill tribes. Also, further study should compare the musical culture of other Hmong groups with the groups of the northern region of the Lao People's Democratic Republic.

\section{References}

Boas, F. (1914). Mythology and folktales of the North American Indians. Journal of American Folklore, 27(106), 374-410.

Chantawanitch S., \& Pliensri, T. (2010). The Lao Hmong in Thailand: State policies and operations [in Thai]. Bangkok: Arun Publications.

Chonpairote, M. (2008). Method of conserving, restoring and developing the identity and customs of the Kula ethnic group in Isan [in Thai]. PhD thesis, Mahasarakham University, Mahasarakham.

Culas, C. (1975). Migrants, runaways and opium growers: Origins of the Hmong in Laos and Hmong hill tribes. Bangkok: The Office of Secretary Committee National Psychology Operation.

Juntong, B. (2003). Music of the Hmong people, Ban Sobpet Tawangpa District, Nan Province [in Thai]. PhD thesis, Srinakharinwirot University, Bangkok.

Kaewla, N. (2011). Music of Hmong people in the developement area of the Luang Nong Hoi program, Mae Raem Sub-district, Mae Rim District, Chiang Mai Province [in Thai]. Bangkok: The National Research Council.

Mottin, J. (1980). History of Hmong. Bangkok: Odeon Store

Patagratch, N. (2005). Local tribes [in Thai]. Bangkok: Feung-Faa Publications.

Radcliffe-Brown, A. R. (1940). On social structure. Journal of the Royal Anthropological Institute of Great Britain and Ireland, 70(1).

Vorreiter, V. (2009). Songs of memory. Chiang Mai: Resonance.

\section{Copyrights}

Copyright for this article is retained by the author(s), with first publication rights granted to the journal.

This is an open-access article distributed under the terms and conditions of the Creative Commons Attribution license (http://creativecommons.org/licenses/by/3.0/). 